\title{
ANIMATED SPACE
}

Since early days, the moving images of animated film have suggested a spatial freedom that challenges the limits of the photographic and traditional filmic space.

When, in 1914, Winsor McCay drew himself onto the landscape to interact with Gertie, he was initiating a practice of expanding the space(s) we live in through the use of the animated image that lasts until today.

Animation's wide aesthetic and technical malleability, and its innate ability to suggest metamorphosis and unrest, has led its practice to cross boundaries and engage with the space beyond the limits of the traditional screen.

And, while early rubber hose animation projected the uncertainty of the accelerating modern life onto the screen, contemporary animation is now seamlessly embedded in our lives, redesigning the facades of our cities, expanding both our intimate spaces and our theatrical experiences, enabling the digital devices to enhance our creative processes.

From straightforward projection and site-specific installation work to video-mapping and VR, with the city landscape becoming the ultimate animation canvas and an animated body in itself, this issue of the International Journal of Film and Media Arts is dedicated to practices of expanded animation that either engage with the physical space or make use of space as a narrative device. 
In "Fragmented Narratives: Exploring Storytelling Approaches for Animation in Spatial Context", Lea Vidakovic addresses narrative forms that employ physical space as part of the storytelling process, mapping an historical perspective, from early cinema to the white cube of the contemporary gallery. Referring to her own practice and works from Tabaimo, Rose Bond and William Kentridge among others, Vidakovic examines how narrative structures have changed over time, suggesting non-linear alternatives may be explored when animation is screened outside the traditional screen.

Başak Kaptan Şiray maps out an historical perspective of abstract moving image works that stimulate a tactile perception, disrupting the hegemony of vision over the other senses. Her survey ranges from the early works of Eggeling, Ruttman and Richter, to contemporary practitioners like Refik Anadol. Siray proposes that such a focus on the haptic will enable the audience to transcend the traditional screen experience and stimulate new spatial and temporal qualities of the image.

Also within the practice of abstract animation, Dirk de Bruyn reviews the work of independent director Max Hattler, inscribing it in an historical tradition of abstract formalism, where patterns and modular composition reflect hidden spatial connections. For de Bruyn, Hattler's digital architectures respond to the technological environment he inhabits and experiences, and help us make sense of the image and information overloaded world we live in.

Rose Bond takes us from the exterior world to that of theatrical space: in her article, the author and filmmaker reflects on her non-linear strategies, the documentary elements and influences that inspired her response to the equally inspiring and challenging Sinfonia, composed by Luciano Berio in the eventful year of 1968. Bond provides an insight into the aesthetic options and cinematic mechanics that orchestrate the visual puzzle of her multi-screen animated projection for the Oregon Symphony performance of Berio's masterpiece".
In "Animated urban surfaces: spatial augmented reality in public discourse", Martina Tritthart addresses architecture as screen for animated content. Through case studies by selected artists like Corrie Francis Parks, Pablo Valbuena and Robert Seidel, Tritthart analyses the role of animation as a socially engaged and activist practice, counterbalancing the commercialization of public space.

Continuing to address urban space, Jana Rogoff reflects on the ways in which the short animated films of Neumann, Rybcziński, Barta, and Smetana, engage critically with Eastern bloc urban planning and the transformation of city space. Rogoff compellingly presents space as an "event", rather than a simple support to character action, and animation as a tool for raising sociopolitical concerns and questioning the boundaries between public, personal, and political spaces.

The last three articles address digital animation and augmented reality: Schweiger, Wimmer, Nagler, and Schlagowski take us further into the interconnections between animation and the cityscape. They analyse the impact of the holographic recreation of a building destroyed during the Second World War in the city centre of Augsburg. Their research details the reactions of city dwellers and anticipates the fascinating potential of augmented reality for architectural investigation, urban planning, and its social implications.

Henry Melki is also interested in the way Virtual Reality (VR) exacts a reaction from its audience: considering that VR audiences share the same space as actors in a play, the author argues that VR should be associated with theatre and not with film or animation. Using two case study VR narratives, "Gloomy Eyes" and "The Beast", Melki's article utilizes theatrical criteria to propose a holistic view to approach VR literacy.

We conclude with Wastyn, Malliet and Geerts' study on the use and potential of VR as a production environment for animation. Like Melki, the authors identify the VR audience as 
active participants and, referring to a series of workshops developed within their Painting with Light project, investigate the use of a virtual environment, where interface restrictions are simplified and improvisation and collaboration are fostered, to generate a shared creative dimension.

From the site-specific, theatrical, and architectural to the virtual environment, the views included and explored in this collection of articles confirm a wide range of approaches that, leaving the traditional screen behind, propose expanded, spatial ways of working with and thinking about animation through alternative forms of narrative construction, suggest different ways to look and organize the cityscape, and anticipate shared virtual and creative production spaces. 